\section{Gender and science}

$\mathrm{D}$ espite some progress in recent years, achieving gender equality in scientific research remains an important challenge for policy-makers and the scientific community at large. Concordantly, the promotion of women at all levels of academic research has become a priority on the science agendas of many national and international political institutions. Although the number of female scientists has increased, true gender equality has not been achieved. Overall, women are still under-represented in many research fields, generally receive lower salaries, are less likely to have fulltime contracts and have fewer opportunities to gain influential positions than their male colleagues.

Together with other policy-making institutions, EU member states and other stakeholders, the European Commission (EC; Brussels, Belgium) promotes research into the specific problems that female scientists face and suggests measures to increase the participation of women in academic science. By introducing the Gender Action Plans (GAPs) within the Sixth Framework Programme (FP6), the EC is pursuing two objectives: to promote the participation of female scientists in FP activities, and to ensure that gender issues are properly addressed in EC-funded research. GAPs include specific actions to gather genderrelated statistical data about the workforce within the research networks and to monitor progress towards gender balance.

A vast amount of statistical data relating to gender issues in research shows that women are still suffering from two types of discrimination: horizontal segregation-women are significantly represented only in certain fields, notably biology and medicine-and vertical discrimination, which is commonly described as the 'glass ceiling' or 'leaky pipeline' (EC, 2006). Although women and men begin their scientific careers in fairly equal numbers across Europe, the ratio of women to men gradually decreases higher up the career ladder. Although the statistics highlight the problem, the data need to be refined with comprehensive studies (Ledin et al, 2007, Martinez et al, 2007) that investigate job-related perceptions and motivations, opinions and potential prejudices in order to define feasible strategies and actions to increase the involvement of women at all levels of research.

In light of this, we conducted a survey of two large, closely linked, European research networks-FP6 Network of Excellence EADGENE and FP6 Integrated Project SABRE - to assess the gender-related differences in recruitment, career paths and career advancement, and the perceptions and attitudes of researchers towards genderrelated issues in their research field - animal genomics in this case-and in their institute. Both networks seem to be virtuous with regard to gender because they meet and exceed the target quota of women employees $-40 \%$ of all researchers, as recommended by the EC (EC, 1999). Nevertheless, our preliminary census indicated that both networks have a lower representation of women among experienced scientists compared with early-stage researchers.

We designed an online multiple-choice structured questionnaire based on standard sociological criteria (Corbetta, 2003) to be answered by research, technical and administrative staff at the institutions involved in the two networks. The survey included questions about the researchers' careers and attitudes; job profile, including structural features such as gender, age, education and marital status; job satisfaction with respect to their position, type of contract, number of working hours and the quality of their working relationships with colleagues; attitudes and perceptions with regard to gender issues; and their expectations of participation and involvement in gender-related activities promoted within the research networks. In total, 143 people participated in the survey: 76 males $(53.1 \%)$ and 67 females (46.9\%).

Our data confirm trends seen at the wider European level. First, both male and female respondents positively valued the intellectual qualities and research skills of female researchers. Second, the majority of those who answered believed that most scientific disciplines are equally suitable for both men and women-although mathematics, engineering and physics are considered more 'masculine' by our respondents-and perceived that a scientific education is an important tool for the personal and professional progress of both men and women.

However, there were inevitable gender imbalances among the networks' researchers. For example, higher positions-such as head of department or institute director-were most commonly held by men; only a few of the women said that they had a leading role within their institution, whereas the majority of women claimed to have little opportunity to make decisions regarding organization and project activities-almost half of the female respondents complained about this. Moreover, $83.6 \%$ of the men were employed on a permanent contract compared with only $56 \%$ of the women. This means that female researchers are more likely to hold temporary contracts or scholarships, which often means lower job satisfaction and higher levels of stress. Indeed, 26\% of the women were dissatisfied with their contractual situation, compared with $16.1 \%$ of the men. Gender disparities in career opportunities and contract conditions could be partly related to age-female respondents were, on average, younger than men-or to family issues (Ledin et al, 2007; Martinez et al, 2007). Our results also confirm that many women participate more actively in research in the early stages of their career, but lower their professional ambitions in order to raise children. It is notable that more than seven out of ten women and six out of ten men believed that a scientific career is difficult to combine with childcare. According to the respondents, the research institutions involved in both networks have already taken some initial steps to meet the needs of their female employees, but these efforts are not perceived to be sufficient by many respondents, particularly women, who think that further improvements, in terms of policies and staff management, are necessary.

The respondents also identified several obstacles to gender equality (Table 1), one of which was a lack of awareness of discrimination against women by some 
male researchers. Whether this is due to a limited ability to perceive gender inequalities or to a certain reticence to admit the existence of such inequalities needs to be explored further. In addition, both women and men pointed out the difficulties of combining a job with family responsibilities. Interestingly, however, when asked about their own situation, several of the female respondents were rather or fully satisfied with the way in which their own institution allows them to accommodate both a job and a family. It should be remembered, however, that many women in EADGENE and SABRE are either unmarried or not living with a partner, or do not have children.

The survey also revealed significant differences between the way in which male and female scientists generally evaluate genderrelated issues. Specifically, women seem to be more critical of gender-based relationships within research institutions. The overwhelming majority of women $(76.6 \%)$ agreed with the strong statement that 'research is ruled by men', compared with $47.3 \%$ of the men. In addition, more than $75 \%$ of female interviewees believed that women are too often relegated to administrative or subordinate roles, whereas only around $33 \%$ of their male colleagues shared this opinion. These notable differences in perceptions could be because men either find it difficult to recognize an imbalance between themselves and their female colleagues, or they prefer not to admit the problem.

Another relevant finding from our survey concerns self-confidence. Of the women involved in the questionnaire, $57.4 \%$-compared with $27.3 \%$ of the men-believed that female scientists are not able to reach higher positions in science because they are less determined to fight for their careers or are unwilling to adopt more competitive behaviour, which they consider to be a typical characteristic of the male gender.

Our results raise several policy issues. According to our survey, training scientists should focus not only on scientific and technical issues, but also on psychological ones. It confirms a need to encourage women to develop a more positive attitude towards themselves and their work and, even more importantly, gender policies should go beyond practical measures to better combine work and family responsibilities, and should also attempt to overcome the traditional

Table 1 Main obstacles perceived by researchers to hinder gender equality in science

\begin{tabular}{|c|c|c|}
\hline & \multicolumn{2}{|c|}{ Strongly or rather agree $(\%)$} \\
\hline & Females & Males \\
\hline A scientific career is difficult to conciliate with child care & 72.3 & 58.9 \\
\hline $\begin{array}{l}\text { Women are less gifted than men for doing research in the } \\
\text { sciences }\end{array}$ & 15.6 & 3.6 \\
\hline Research is ruled by men & 76.6 & 47.3 \\
\hline $\begin{array}{l}\text { Men have more often than women the necessary skills to } \\
\text { hold positions of responsibility }\end{array}$ & 19.1 & 16.1 \\
\hline Women are less willing than men to fight for their career & 57.4 & 27.3 \\
\hline $\begin{array}{l}\text { In research, women are too often relegated to administrative } \\
\text { or subordinate roles }\end{array}$ & 76.6 & 33.9 \\
\hline
\end{tabular}

views of career paths and leadership qualities that have been largely determined in a male-dominated environment. For example, recruitment and promotion criteria should include and recognize qualities such as training colleagues, sharing knowledge and skills, openness to interdisciplinary research, curiosity and open-mindedness, and cooperative rather than competitive attitudes.

From this perspective, European research projects such as EADGENE and SABRE have the potential to strengthen the contribution of women to research development and decision-making. Some initial steps have already been taken within the two networks to improve gender equality. First, a mentoring programme has been designed based on the results of a survey conducted to help plan an effective programme to fit the needs and expectations of female scientists. Second, specific criteria in line with the GAPs are regularly applied in selecting recipients-both at early and advanced career stages - to receive training and mobility funds. Third, a public event was organized at the Parco Tecnologico Padano in June 2007-the European Workshop Mind the GAP 2007-to highlight to members of the scientific community, from young researchers to established professors, the 'gaps' in opportunities that still hamper the progress of women in science.

Mentoring activities such as these, together with opportunities for male and female researchers to visit other research institutions, have contact with more experienced researchers, as well as events that raise public awareness of the issues, are all appropriate starting points to make gender not only a matter for individual careers, but also a structural concern for research institutions and teams in general.

\section{ACKNOWLEDGEMENTS}

The survey was co-financed by the European Commission, within the 6th Framework Programme, through contract numbers FOOD-CT-2004-506416 (EADGENE) and FOOD-CT-2006-016250 (SABRE). We are grateful to the EADGENE and SABRE scientists for the completion of the surveys and the EADGENE and SABRE staff for their assistance, in particular Sandrine Ayuso, Bonne Beerda, Caroline Channing and Toine Roozen. Thanks to Lorenzo Beltrami (University of Trento, Italy) for his help with the statistical analysis of EADGENE data. A special thanks to Joan K. Lunney (USDA, USA) for critical advice and support. The text represents the authors' views and does not necessarily represent a position of the European Commission.

\section{REFERENCES}

Corbetta P (2003) La Ricerca Sociale: Metodologia e Tecniche. Bologna, Italy: II Mulino

EC (1999) Communication "Women and ScienceMobilising Women to Enrich European Research"; COM(1999). Brussels, Belgium: European Commission

EC (2006) She Figures 2006, Women and Science, Statistics and Indicators. Brussels, Belgium: European Commission

Ledin A, Bornmann L, Gannon F, Wallon G (2007) A persistent problem. Traditional gender roles hold back female scientists. EMBO Rep 8: 982-987

Martinez E et al (2007) Falling off the academic bandwagon. Women are more likely to quit at the postdoc to principal investigator transition. EMBO Rep 8: 977-981
Simona Palermo \& Elisabetta Giuffra are at Parco Tecnologico Padano in Lodi, Italy. Valeria Arzenton \& Massimiano Bucchi are at Observa-Science in Society, in Vicenza, Italy.
E-mail: simona.palermo@tecnoparco.org doi:10.1038/embor.2008.82 